\title{
Tissue expression of the nuclear progesterone receptor in male non-human primates and men
}

\author{
C Marc Luetjens, Aditya Didolkar, Sabine Kliesch ${ }^{1}$, Werner Paulus ${ }^{2}$, \\ Astrid Jeibmann ${ }^{2}$, Werner Böcker ${ }^{3}$, Eberhard Nieschlag \\ and Manuela Simoni \\ Institute of Reproductive Medicine, University Hospitals, Domagk-Strasse 11, D-48149 Münster, Germany \\ ${ }^{1}$ Urology Clinic, University Hospitals, Albert-Schweiter-Strasse 33, D-48149 Münster, Germany \\ ${ }^{2}$ Institute of Neuropathology, University Hospitals, Domagk-Strasse 9, D-48149 Münster, Germany \\ ${ }^{3}$ Gerhard-Domagk Institute of Pathology, University Hospitals, Domagk-Strasse 7, D-48149 Münster, Germany \\ (Requests for offprints should be addressed to E Nieschlag; Email: Eberhard.Nieschlag@ukmuenster.de)
}

\begin{abstract}
In females, progesterone is associated with reproductive functions. In males, its role and the expression of its genomic receptor are not very well understood. In attempts to achieve a hormonal male contraceptive method, gestagens are used to downregulate gonadotropin and sperm production. It is therefore essential to understand the mechanism of action of progesterone at the molecular level in males, especially in primates. This investigation was undertaken: (a) to determine whether the genomic progesterone receptor is expressed in males; and (b) to locate it in various organs that are potential targets of gestagens. Human tissues were obtained at surgery for benign prostatic hyperplasia or prostate cancer and at autopsy. Non-human primate tissues were obtained at autopsy. This study was performed by analyzing the
\end{abstract}

genomic progesterone receptor by immunohistochemistry, Western blot and RT-PCR. The nuclear progesterone receptor was expressed in pituitary and hypothalamus of both monkeys and men. In the testis progesterone receptor expression was found in a few peritubular and interstitial cells, but not in germ cells. In addition, expression was detected in the epididymis, prostate and male mammary gland. Reverse transcriptase (RT)-PCR experiments indicated that progesterone receptor $\mathrm{A}$ and $\mathrm{B}$ are expressed in all tissues analyzed. These data exclude direct genomic effects of gestagens at the spermatogenic level but indicate that a male contraceptive based on gestagens might have some effects on other tissues, such as the epididymis, prostate and mammary gland.

Journal of Endocrinology (2006) 189, 529-539

\section{Introduction}

In males, the expression of the genomic progesterone receptor (PR) and the physiological function of progesterone at the molecular level are not well understood (Oettel \& Mukhopadhyay 2004). Recently a nongenomic PR has been described which can be found in the membrane of sperm from a wide range of vertebrates (Zhu et al. 2003). Well-known non-genomic actions of the PR include stimulating sperm acrosome reaction and fertilization and other functions (Baldi et al. 1995, Alexander et al. 1996). In females, target organs of progesterone are ovary, uterus and mammary gland. In these organs the genomic PR is expressed in two major isoforms, called PR-A and PR-B, which are the product of two different transcriptional start sites and differ by an $\mathrm{N}$-terminal extension of about 165 amino acids in the PR-B (Conneely et al. 2001). The mature PR-A and PR-B proteins have a molecular mass of about 94 and
$116 \mathrm{kDa}$ respectively. Luteinizing hormone $(\mathrm{LH})$ induces $\mathrm{PR}$ expression in granulosa cells. PR-A and PR-B have partly different functions: in general PR-A is a repressor of PR-B. PR-B is a strong activator of target genes. The relative expression of $\mathrm{PR}-\mathrm{A}$ and $\mathrm{PR}-\mathrm{B}$ changes in different tissues and determines the type of action of gestagens. A shorter $(60 \mathrm{kDa})$ isoform, called PR-C, has also been described (Wei \& Miner 1994). The PR-C is translated from an in-frame ATG codon at the C-terminus of exon 2 of the PR gene and comprises the second zinc finger of the DNA-binding domain, the hormone binding domain and sequences for dimerization and nuclear localization. The PR-C has been shown to be localized in the cytoplasm, to bind progesterone and to migrate to the nucleus but is not capable of DNA binding. However, the PR-C can dimerize with the other isoforms, thereby modulating progesterone action by increasing the transcriptional activity of PR-A and PR-B (Wei et al. 1996). 
Besides acting as a steroidogenic precursor and stimulating acrosome reaction (reviewed by Lösel et al. 2003), progesterone has no known major function in the male, and progesterone receptor-knock out (PRKO) male mice are phenotypically normal and fertile (Lydon et al. 1995). However, such male mice have elevated LH concentrations, suggesting a function of progesterone in the control of LH secretion (Schneider et al. 1999), an effect exploited in hormonal male contraception (Kamischke \& Nieschlag 2004). In the current approach, in addition to testosterone, hormonal male contraceptives contain a gestagen (Nieschlag et al. 2003, Kamischke \& Nieschlag 2004) which is exploited for gonadotropin suppressive properties. The feedback regulation of the hypothalamo-pituitarygonadal axis by gestagens involves both inhibition of pulsatile gonadotropin-releasing hormone $(\mathrm{GnRH})$ secretion and repression of $\mathrm{GnRH}$ receptor transcription via a progesterone responsive element present in the $\mathrm{GnRH}$ receptor promoter (Cheng et al. 2001, An et al. 2004).

It is not currently known which type of PR mediates progesterone and gestagen action in the male at the hypothalamo-pituitary level and in other organs. It was postulated that gestagen administered to men for contraceptive purposes might have a direct testicular and/or epididymal effect on spermatogenesis and sperm maturation (Kamischke et al. 2000a). Data on localization of the nuclear PR in the testis and other male organs, however, are scant. Dube and Tremblay (1979), found the PR in the testes of chickens and in patients with testicular feminization. In 1995, by reverse transcriptase (RT)-PCR, PR was found to be very highly expressed in the testis as well as the prostate of cynomolgus monkeys (Heikinheimo et al. 1995); however, no cellular localization study was performed. Very recently, strong expression of nuclear PR in the human seminiferous epithelium and testis was claimed (Shah et al. 2005). However, a careful review of the data presented in the human testis suggests the possibility of immunohistochemical staining artefacts and unspecific Western blot bands (Shah et al. 2005). In addition, we recently failed to demonstrate a direct biological testicular effect of norethisterone enanthate on the testis (Junaidi et al. 2005).

Characterizing the expression pattern of genomic PR in the male is necessary to design drugs acting selectively to suppress gonadotropins and spermatogenesis while avoiding side effects. In this study we analyzed nuclear PR expression in various reproductive and non-reproductive organs obtained from men and, as experimental models, from two non-human primate species, the marmoset and the cynomolgus monkey.

\section{Materials and Methods}

Tissues

Formaldehyde-fixed (4\%), paraffin-embedded, male human tissues (liver, kidney, lung, spleen, heart, duodenum, bladder, mammary gland, seminal vesicle, epidermis, pituitary and hypothalamus, $n=3$ ) and human ovary and placenta were archived material of the Institute of Pathology and of the Institute of Neuropathology, University Hospitals, Münster, Germany. Fresh human testes and epididymides were obtained at surgery from patients orchidectomized because of prostate cancer. These patients may have had an antiandrogen treatment prior to the surgery but, irrespective of this, the histology results were similar. Fresh prostate tissue samples were obtained at surgery for benign prostatic hyperplasia from three patients at the Urology Clinic, University Hospitals, Münster, Germany. Tissues were fixed in Bouin's solution for $4 \mathrm{~h}$ or snap frozen. Informed consent for the use of leftover tissues was provided by the patients, as required by the Ethics Committee of the Medical Faculty and State Medical Board. All tissues from both monkey species (cynomolgus, Macaca fascicularis; marmoset, Callithrix jacchus) were obtained at autopsy of male animals, euthanized for reasons independent from the present study, from our primate colony (licensed by the State Board according to the German Law for Animal Care and Protection). The monkey tissue samples were fixed in Bouin's solution for $4 \mathrm{~h}$ or snap frozen immediately after dissection. All chemically fixed tissues were embedded in paraffin, sectioned at $4 \mu \mathrm{m}$ and used for immunohistochemistry. Snap-frozen tissues were kept at $-80{ }^{\circ} \mathrm{C}$ until use for Western blotting or RNA extraction. The human breast cancer cell line T47D was used as the positive control in all experiments.

\section{Immunohistochemistry}

The following tissues were tested immunohistochemically for the presence of the genomic PR: liver, kidney, lung, spleen, heart, duodenum, bladder, mammary gland, testis, epididymis, prostate, seminal vesicle, epidermis, pituitary and hypothalamus. All sections were treated equally. After deparaffinization and rehydration five different commercially available primary antibodies $(\mathrm{Ab})$ for the human PR (four monoclonal, one polyclonal) were applied: mouse anti-PR Ab-3 (catalog number MS-193-P0) and mouse anti-PR Ab-7 (catalog number MS-197-P0) from Neomarkers, Fremont, CA, USA; mouse anti-PR (catalog number 2145) from Immunotech, Marseille, France; mouse anti-PR (catalog number NP008) from DAKO Diagnostika, Hamburg, Germany; rabbit anti-PR (catalog number A0098) also from DAKO Diagnostika. Antibodies were applied for $30 \mathrm{~min}$ at room temperature in blocking buffer. After washing, DAKO-LSAB 2 System (DAKO Diagnostika) was added for $30 \mathrm{~min}$, followed by a washing step and by incubation with diaminobenzidene (DAB; DAKO Diagnostika) for $20 \mathrm{~min}$. Controls for all immunohistochemical staining procedures were performed by omitting the primary antibody on adjacent 


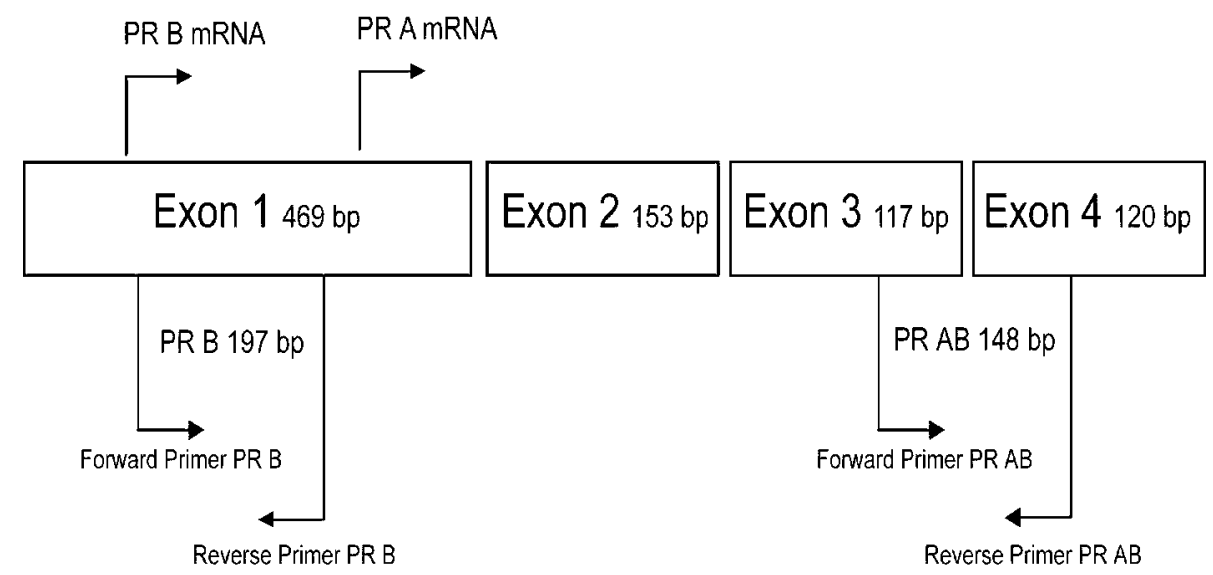

Figure 1 Schematic representation of the genomic organization of the PR gene covering exons 1 to 4. The exon sizes (nucleotides) are given in the different exon boxes. The two different primers are named $B$ and $A B$ and the transcript sizes are given below the primers. The starting and ending points (nucleotide position in the different exons) are given in the exon boxes. The primer pair for primer $\mathrm{AB}$ spans exon 3 and 4.

sections. The sections were counterstained with hematoxylin for $10 \mathrm{~s}$ and mounted under cover slips with Dako Faramount (DAKO Diagnostika) prior to observation using an upright microscope (Axioskop, Zeiss, Oberkochen, Germany) at different magnifications (objectives $\times 25$ and $\times 40$ ). Digital images of equal exposure were acquired with a CCD camera (Axiocam) controlled by image software (Axiovision).

\section{Western blotting}

Protein concentrations in cell homogenates in RIPA buffer were determined by BCA-protein assay (reagents from Pierce, Rockford, IL, USA). For electrophoresis NuPage pre-cast gels (Invitrogen) were run at $200 \mathrm{~V}$ and transferred at $30 \mathrm{~V}$ for $1 \mathrm{~h}$ to Hybond ECL-membranes (Amersham). After blocking with 5\% milk powder in $1 \times$ PBS/0.01\% Tween 20 blots were incubated overnight with primary anti-PR antibodies, washed and incubated with the appropriate secondary, horseradish peroxidase (HRP)-conjugated Ab (Sigma; A9044/1:30000) for $1 \mathrm{~h}$. The mouse anti-PR Ab-3 (catalog number MS-193-P0) and anti-PR Ab-7 (catalog number MS-197-P0) from Neomarkers, and the mouse anti-PR (catalog number NP008) and rabbit anti-PR (catalog number A0098) from DAKO Diagnostika, were applied in Western blots, with similar results. As positive controls, a lysate from the breast cancer T47D cell line, obtained from CLS Heidelberg, Germany, and protein extracts from human and cynomolgus endometrium were used. Enhanced chemiluminescent detection was performed using the ECL plus kit (Amersham). In five repeated experiments, 10-20 $\mu \mathrm{g}$ T47D cell lysates and various concentrations of tissue protein extracts (up to $800 \mu \mathrm{g}$ ) were used.

\section{$R T-P C R$}

RNA was extracted from tissue stored at $-80{ }^{\circ} \mathrm{C}$ using a commercial kit (Ultraspec, Biotecx Laboratories, Houston, TX, USA). In addition, we used commercially available mRNA from human testis, epididymis and prostate (Biocat, Heidelberg, Germany). cDNA synthesis was performed using random primer examers. First-strand cDNA was synthesized starting from $2 \mu \mathrm{g}$ total RNA, $1 \mu \mathrm{l}$ random primers (Promega) and $12.5 \mu \mathrm{l}$ diethyl pyrocarbonate (DEPC) $\mathrm{H}_{2} \mathrm{O}$ for $5 \mathrm{~min}$ at $65^{\circ} \mathrm{C}$. Master mix $(7 \mu \mathrm{l})$ (containing $2 \mu \mathrm{l}$ dNTPs, $4 \mu \mathrm{l}$ M-MLV RT $5 \times$ buffer, $1 \mu \mathrm{l}$ RNasin and $0.5 \mu \mathrm{l}$ reverse transcriptase; all reagents from Promega) was added to a final volume of $20 \mu \mathrm{l}$ and the reaction was completed for $1 \mathrm{~h}$ at $37^{\circ} \mathrm{C}$. Reactions were then frozen until use.

Amplification of PR-B was performed using the following primers in exon 1: PR-B forward primer, $5^{\prime}$-CCT GAAGTTTCGGCCATACCT-3'; PR-B reverse primer, 5'-AGCAGTCCGCTGTCCTTTTCT-3'. These primers were selected in a region of exon 1 presenting about $75 \%$ sequence identity between human, rat and mouse PR and produce an amplicon of $197 \mathrm{bp}$ (Fig. 1). No marmoset sequence information is available in this genomic region.

Amplification of $\mathrm{PR}-\mathrm{A}+\mathrm{B}$ was performed amplifying a region encompassing parts of exon 3 and 4 using the following primers: $\mathrm{PR}-\mathrm{A}+\mathrm{B}$ forward primer, $5^{\prime}-\mathrm{AGCA}$ TGTCGCCTTAGAAAGTGC-3'; PR-A+B reverse primer, 5'-TAGGGCTTGGCTTTCATTTG-3'. The forward primer is located in exon 3 and presents $99 \%$ identity between human, mouse and rat sequences; the reverse primer, in exon 4 , is $100 \%$ specific for both human and marmoset PR (marmoset accession no. Z86038). 
This primer combination results in an amplicon of 148 bp.

Actin mRNA was amplified using the forward primer 5'-GATGACCCAGATCATGTTTG- ${ }^{\prime}$ and the reverse primer $5^{\prime}$ - GAGCAATGATCTTGATCTTC- $3^{\prime}$.

PR-B and PR-A+B were amplified in a duplex PCR reaction, and actin in a separate simplex PCR reaction. Reactions were performed in a $25 \mu \mathrm{l}$ volume containing $2.5 \mu \mathrm{l} 10 \times$ PCR buffer with $15 \mathrm{mM} \mathrm{MgCl}_{2}$ (Quiagen), $1 \mu \mathrm{l}$ dNTPs (Promega), $1 \mu \mathrm{l}$ of each primer, $5 \mu \mathrm{l} 5 \times \mathrm{Q}$ solution (Quiagen), $0 \cdot 3 \mu \mathrm{l}$ Taq polymerase (5 IU $/ \mu \mathrm{l}$; Quiagen), $2 \mu \mathrm{l}$ cDNA and $8 \cdot 2 \mu \mathrm{l} \mathrm{H}_{2} 0$. PCR was performed in a RoboCycler (Stratagene, Amsterdam, The Netherlands). After initial denaturation $\left(94^{\circ} \mathrm{C}, 2 \mathrm{~min}\right)$ the 30 cycle amplification profile consisted of denaturation at $94{ }^{\circ} \mathrm{C}$ for $50 \mathrm{~s}$, annealing at $58{ }^{\circ} \mathrm{C}$ for $40 \mathrm{~s}$, and extension at $72{ }^{\circ} \mathrm{C}$ for $1 \mathrm{~min}$. After a final extension at $72{ }^{\circ} \mathrm{C}$ for $10 \mathrm{~min}$ and cooling at $6^{\circ} \mathrm{C}$ for $10 \mathrm{~min}$, the amplified DNA products were resolved on a $1 \cdot 8-2 \cdot 0 \%$ agarose gel and visualized by ethidium bromide staining. Negative controls without RNA and without reverse transcriptase were also included in the PCR reaction to test for exogenous DNA contamination. To assure that the PCRamplified DNA observed in the agarose gel represented the gene-specific product of interest, bands of the expected size were isolated (for the human tissues marker number VIII (Roche) and for the non-human primates testes marker 100 bp ladder (Peqlab, Erlangen, Germany)), extracted, purified, cloned and sequenced.

Semi-quantification of the RT-PCR results was performed by image analysis in a Multilmage light cabinet (Biozym, Oldesdorf, Germany). Total fluorescent peak areas were calculated by ChemiImages software (Biozym). All data are expressed as mean \pm S.D

\section{Results}

\section{Immunohistochemistry}

PR expression was first analyzed in all tissues $(n=3$ specimens each tissue) available from the three species by immunohistochemistry. The results are summarized in Table 1 . PR was weakly but consistently expressed in the testis from human, cynomolgus monkey and marmoset (Fig. 2). All three species showed a similar expression pattern within the testis, whereby only very few peritubular and interstitial cell nuclei were positive. In the cynomolgus monkey (Fig. 2c and d), relatively more peritubular cell nuclei of the testis expressed the receptor compared with the human (Fig. 2a and b) and marmoset testis (Fig. 2e and f). In all species the staining was completely confined to the nuclei. No specific staining was ever observed in the seminiferous epithelium with any of the antibodies tested.

The prostate showed the strongest PR staining of all male tissues tested (Table 1). In the human and in
Table 1 PR expression analyzed by immunohistochemistry in human organs and in two different male non-human primate species

\begin{tabular}{|c|c|c|c|}
\hline & Human & Cynomolgus & Marmoset \\
\hline \multicolumn{4}{|l|}{ Organ } \\
\hline Testis & + & + & + \\
\hline Epididymis & + & ++ & + \\
\hline Muscle & - & - & - \\
\hline Pituitary & ++ & ++ & ++ \\
\hline Hypothalamus & + & + & + \\
\hline Prostate & ++ & +++ & +++ \\
\hline Mammary gland & ++ & + & ++ \\
\hline Placenta & +++ & +++ & +++ \\
\hline Ovary & ++++ & ++++ & ++++ \\
\hline
\end{tabular}

The level of expression is indexed by the number of plus characters assigned by the same observer by visual inspection compared with the control tissues (placenta and ovary).

cynomolgus monkey prostate staining was confined to the muscular layer of the stroma, showing strong signal in the nuclei of the smooth muscle cells below the epithelium (Fig. 3a and d). None of the other stromal cells showed staining.

In the epididymis, the PR was found in the peritubular cell nuclei of the monkeys (Fig. $3 \mathrm{~b}$ for marmoset and Fig. 3e for cynomolgus monkey). Only in the cynomolgus epididymis were cells from the epidermal layer also positive for the signal (Fig. 3e). Apical cells occasionally showed a faint signal (not shown).

In the mammary gland, staining was confined to the epithelial layer of male breast ducts which were consistently strongly positive (Fig. 3g, cynomolgus monkey; Fig. 3h, marmoset). All immunohistochemical stainings were accompanied by positive control tissue for all three species, such as placenta or ovarian tissue (Fig. 3c, f and i).

In the hypothalamus and pituitary of the three species, sparse cells were consistently stained for the PR (Fig. 4). The other male organs investigated - i.e. liver, kidney, lung, spleen, heart, duodenum, bladder and epidermis were negative.

\section{Western blotting}

Since the PR antibodies used for the immunohistochemical study do not clearly distinguish between the $\mathrm{PR}$ isoforms $\mathrm{A}, \mathrm{B}$ and $\mathrm{C}, \mathrm{PR}$ expression in selected tissues was further analyzed by Western blotting using the same antibodies as those for immunohistochemistry staining (Fig. 5). Repeated Western blot experiments showed that PR expression is probably too low to allow detection by this method in male tissue extracts. We analyzed: (a) testes from eight different men, from five different cynomolgus monkeys and nine different marmosets; (b) epididymidis from two different men, from two different cynomolgus monkeys and from two different marmosets; (c) prostate 

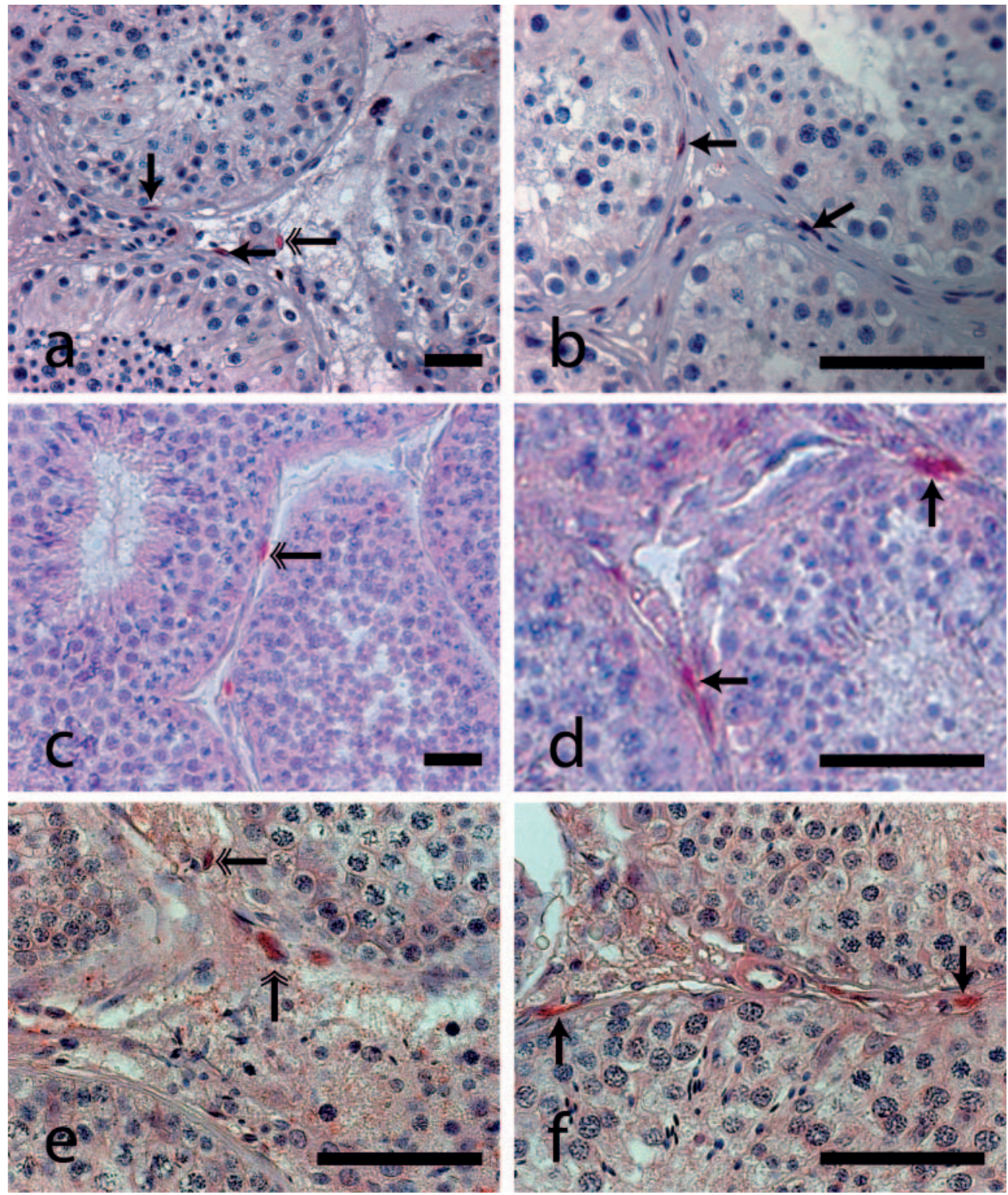

Figure 2 Immunohistochemical expression pattern of the PR in sectioned testes biopsies with complete spermatogenesis at different magnifications counterstained with hematoxylin from men (a and b), cynomolgus monkeys (c and d) and marmosets (e and f). The localization of the PR for all tested species was similar. In all three species the PR expression was weak and exclusively located in the nucleus of some interstitial cells (double-tipped arrow) and in peritubular cells (single-tipped arrow). None of the tubular cells (germ or Sertoli cells) showed any staining for the receptor. Scale bars $=50 \mu \mathrm{m}$.

from three different men with benign prostate hyopplasia $(\mathrm{BPH})$, from two cynomolgus monkeys and from two marmosets. Even using very large amounts of proteins (up to $800 \mu \mathrm{g}$ ) and with all antibodies tested, no band corresponding to PR-A and PR-B could be detected in any tissue in the presence of the positive control (T47D cell extract, endometrium). A faint band, migrating just below the PR-C isoform was detected in the human prostate and in the marmoset epididymis (Fig. 5). However, given the absence of PR-A protein in these tissues, this band might represent a non-specific product.

\section{RT-PCR}

Expression analysis by RT-PCR was performed using primers designed to detect only PR-B and $\mathrm{PR}-\mathrm{A}+\mathrm{B}$ in prostate, testis and epididymis. We analyzed: (a) testes 

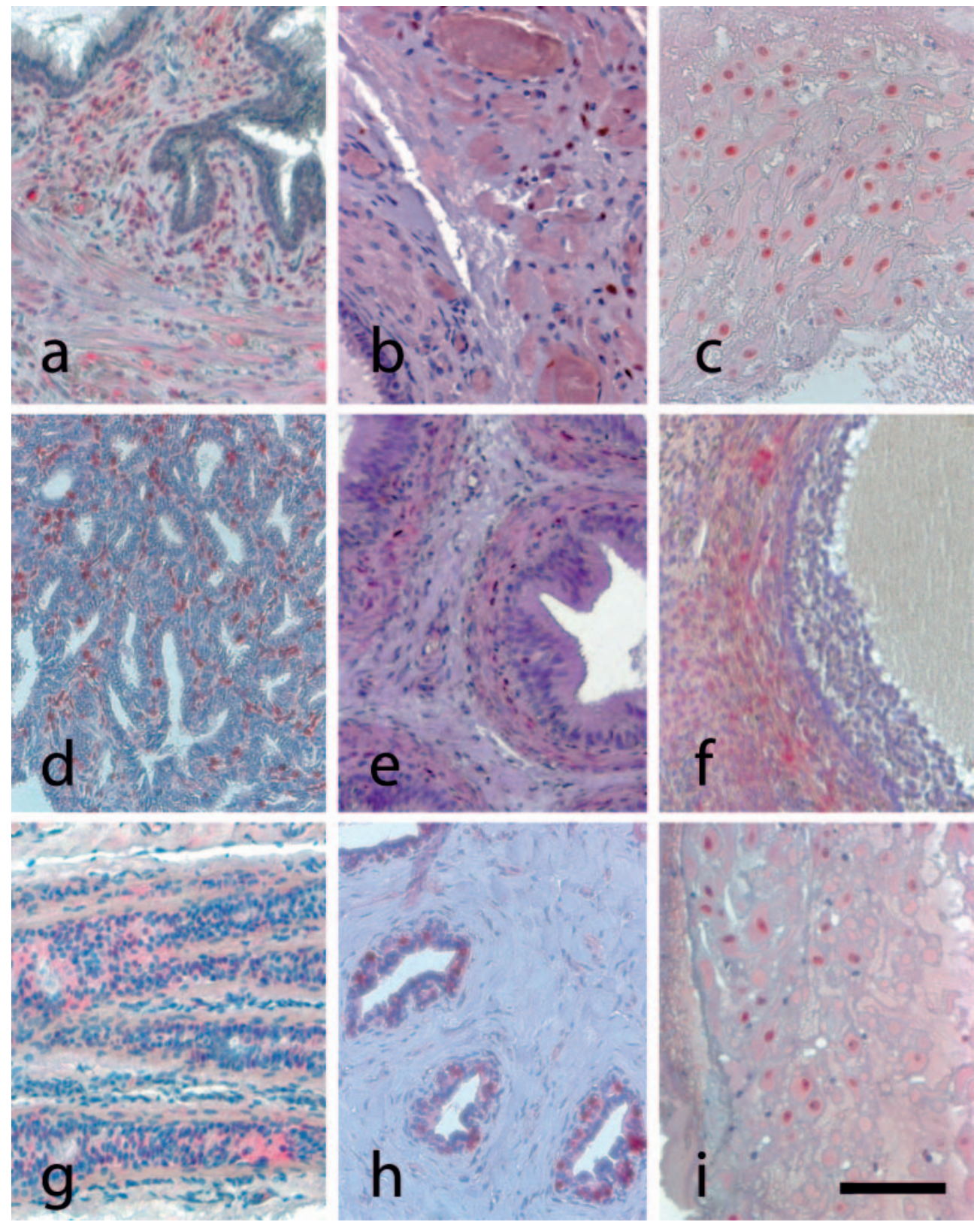

Figure 3 Immunohistochemical localization of the PR in male tissues (left and middle panels) and as control in female tissues (right panels) of the three tested species: human (a and c), cynomolgus monkey $(\mathrm{d}-\mathrm{g})$ and marmoset (b, h and i). The positive nuclei are stained with Newfuchsin and all sections are counterstained with hematoxylin. Smooth muscle cell nuclei of the prostate in men and cynomolgus monkeys are positive for the PR ( $a$ and d) as well as peritubular cell nuclei of the epididymis in marmosets and cynomolgus monkeys, but also some epithelial cells in the cynomolgus epithelial layer (b and e). In the male mammary gland the staining was confined to the epidermal tissue of male breast ducts ( $\mathrm{g}$ for male cynomolgus monkey and $\mathrm{h}$ for male marmosets). All immunohistochemical staining was accompanied by positive control tissue for all three species, such as human placenta (c), ovarian tissue (f) and marmoset placenta (i). Scale bar $=100 \mu \mathrm{m}$.

from four different men, from three different cynomolgus monkeys and three different marmosets; (b) epididymides from two men, from three cynomolgus monkeys and from three marmosets; (c) prostate from three men with $\mathrm{BPH}$, from three cynomolgus monkeys and from three marmosets. The PR expression was ubiquitous, although 

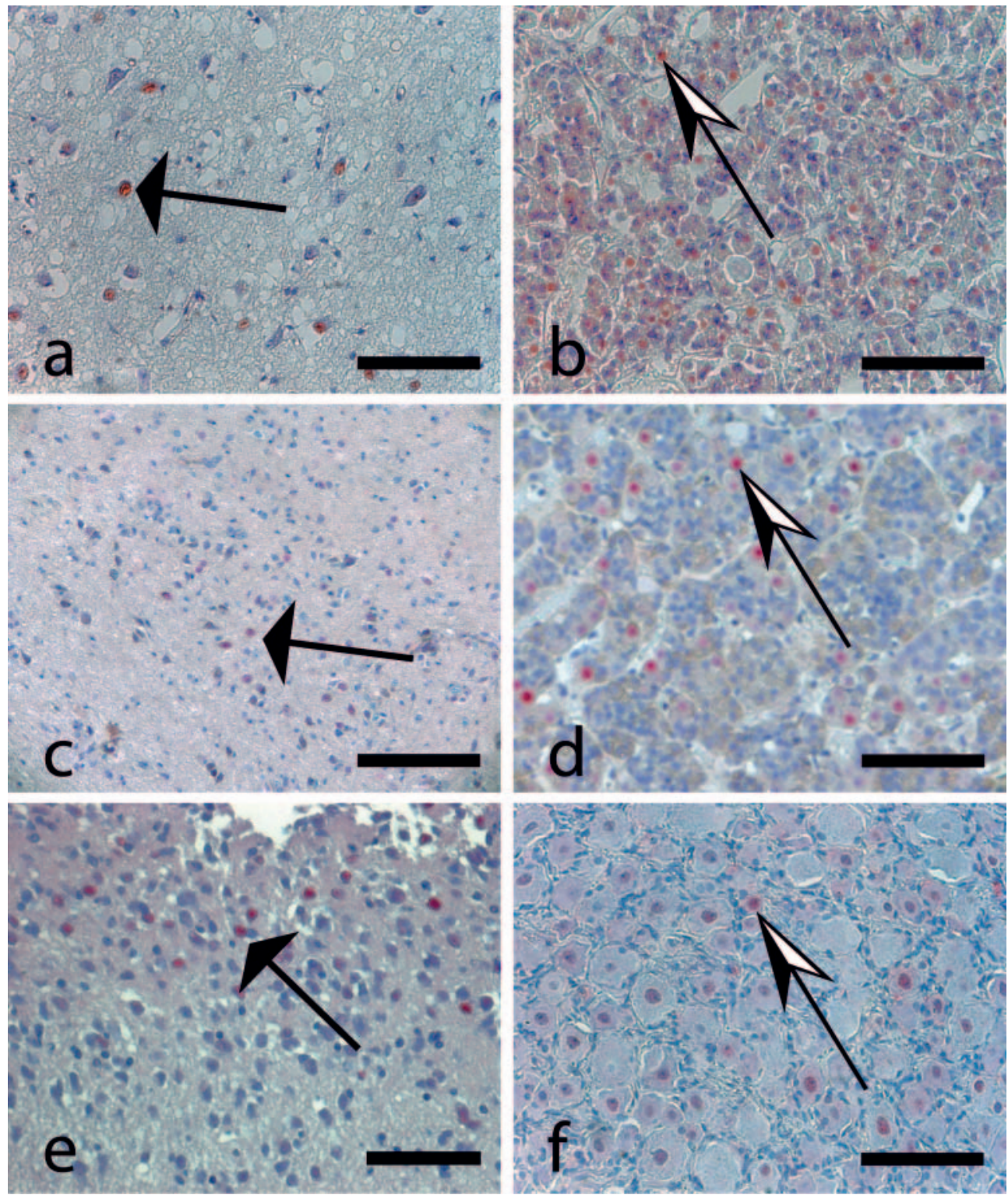

Figure 4 Immunohistochemical expression pattern of the PR of hypothalamus (left panels) and pituitary (right panels) counterstained with hematoxylin from men (a and b), cynomolgus monkeys (c and d) and marmosets (e and f). The localization of the PR for all tested species was similar. In all three species the PR was located in scattered cell nuclei of the hypothalamus (arrow) and in nuclei of epithelial cells of the adenohypophysis (half-open arrow). Scale bars $=100 \mu \mathrm{m}$.

with bands of different intensity, suggesting tissue-specific differences. mRNA expression analysis showed the presence of the PR-B and PR-A+B transcripts in all male human tissues analyzed including the testis, prostate and epididymis (Fig. 6, upper left panel). For the other two primate species both primer sets amplified the mRNA signals in the cynomolgus testis whereby in the marmoset the $\mathrm{PR}-\mathrm{A}+\mathrm{B}$ transcript was very faint and the isoform $\mathrm{PR}$ B was not detected (Fig. 6, bottom left panel). The lack of PR-B amplification in marmoset testis might be due to insufficient specificity for the marmoset sequence, unknown in this region.

Using commercially available, highly purified mRNA, we performed a semi-quantitative expression analysis after normalization against the housekeeping actin gene. In human prostate, epididymis and testis mRNA we detected a transcription level of both PR isoforms which was approximately $0 \cdot 5$-fold of that in T47D cells, without 

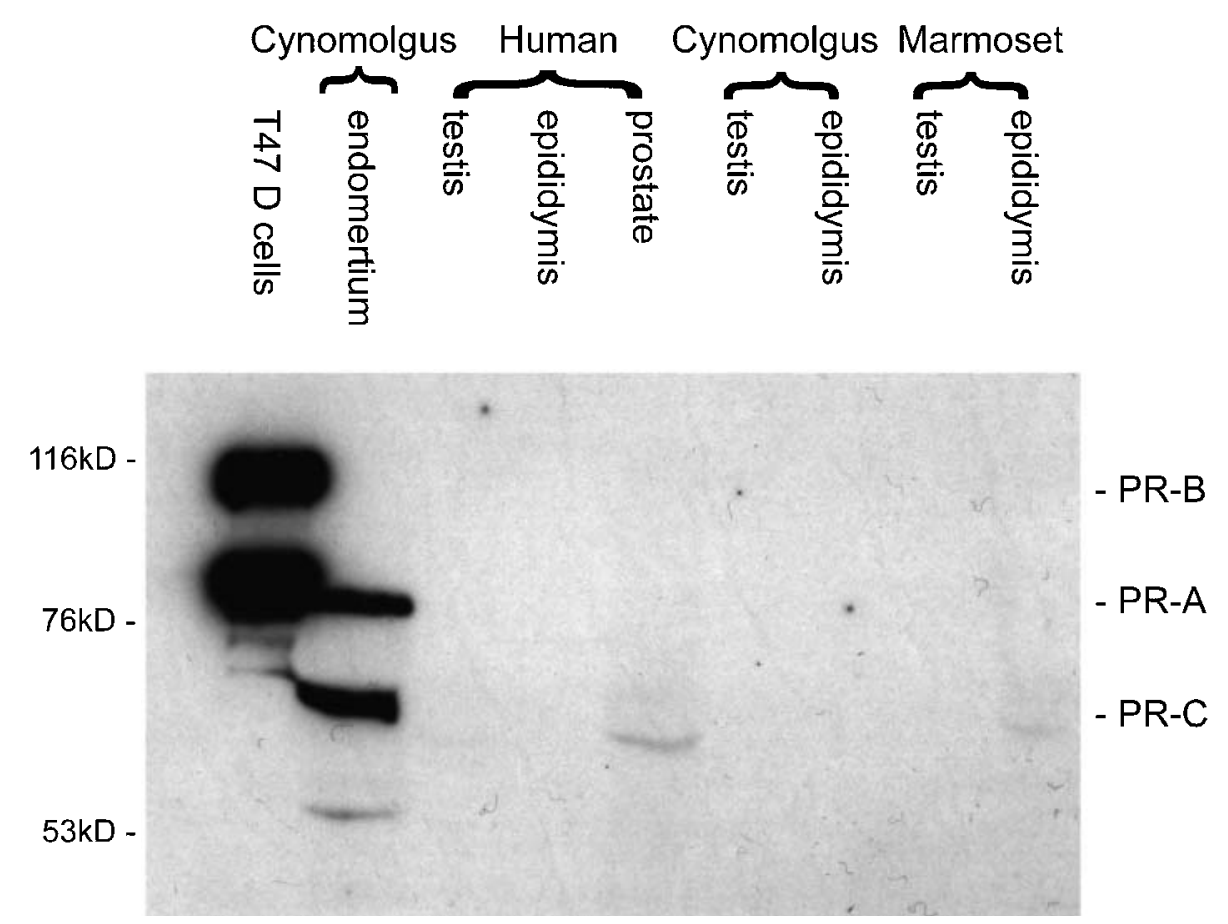

Figure 5 Western blot analysis demonstrates specificity of the PR antibody for different PR isoforms (A, B and C). Although different male tissues were tested - i.e. testis, epididymis and prostate from three different primate species - no specific band was found. Only in the human prostate and in the marmoset epididymis was a faint band of approximately $60 \mathrm{kDa}$ found. T47D cells and cynomolgus endometrium were used as controls.

major differences between isoforms and among tissues (Fig. 6, upper right panel). By analyzing three independent samples of cynomolgus monkey and marmoset testis we detected a similar expression level of both isoforms in the cynomolgus monkey but only the $\mathrm{PR}-\mathrm{A}+\mathrm{B}$ transcripts in the marmoset testis, at an expression level similar to that found in the cynomolgus testis (Fig. 6, lower right panel).

RNA extraction from human pituitaries and hypothalami collected at autopsy was not successful and the PR expression pattern in these tissues could not be determined.

\section{Discussion}

Our study identifies some tissues as potential targets for genomic action of progesterone in men. These tissues include the hypothalamus and the pituitary gland, where progesterone possibly exerts its suppressive effect on gonadotropin secretion, the mammary gland and some organs of the male genital tract - including the prostate and the epididymis - while the presence of the genomic $\mathrm{PR}$ in the testis was rather weak.

Gestagens administered for hormonal male contraception reinforce the gonadotropin suppressive activity of testosterone, resulting in azoospermia. It was suggested that the pituitary-suppressive action of progesterone in males is mediated by the genomic PR but no studies until now localized the genomic PR in human male hypothalami and/or pituitaries (Brady et al. 2003). In this study we show for the first time that the genomic PR is present in sparse nuclei in male hypothalami and pituitaries from humans and non-human primates. Co-localization experiments of the PR with gonadotropin and/or GnRH immunoreactivity are technically very demanding when applied to human specimens and our attempts have not been successful so far. Similarly, we could not determine which PR isoform is expressed in these tissues by RTPCR, due to rapid RNA degradation after death. Our data, however, show that the genomic PR expression is similar in hypothalami and pituitaries of human and non-human primates, providing the basis for future experiments in monkeys. Characterizing the type of PR involved in gonadotropin suppression might be useful for the design of selective PR modulators for male contraception. Recent experiments with a human neuronal medulloblastoma cell line suggested that PR-A and PR-B have different functions in the progesterone-mediated regulation of $\mathrm{GnRH}$ receptor promoter activity (An et al. 2004). Intriguingly, in these cells progesterone stimulated GnRH mRNA transcription, showing the complexity of 

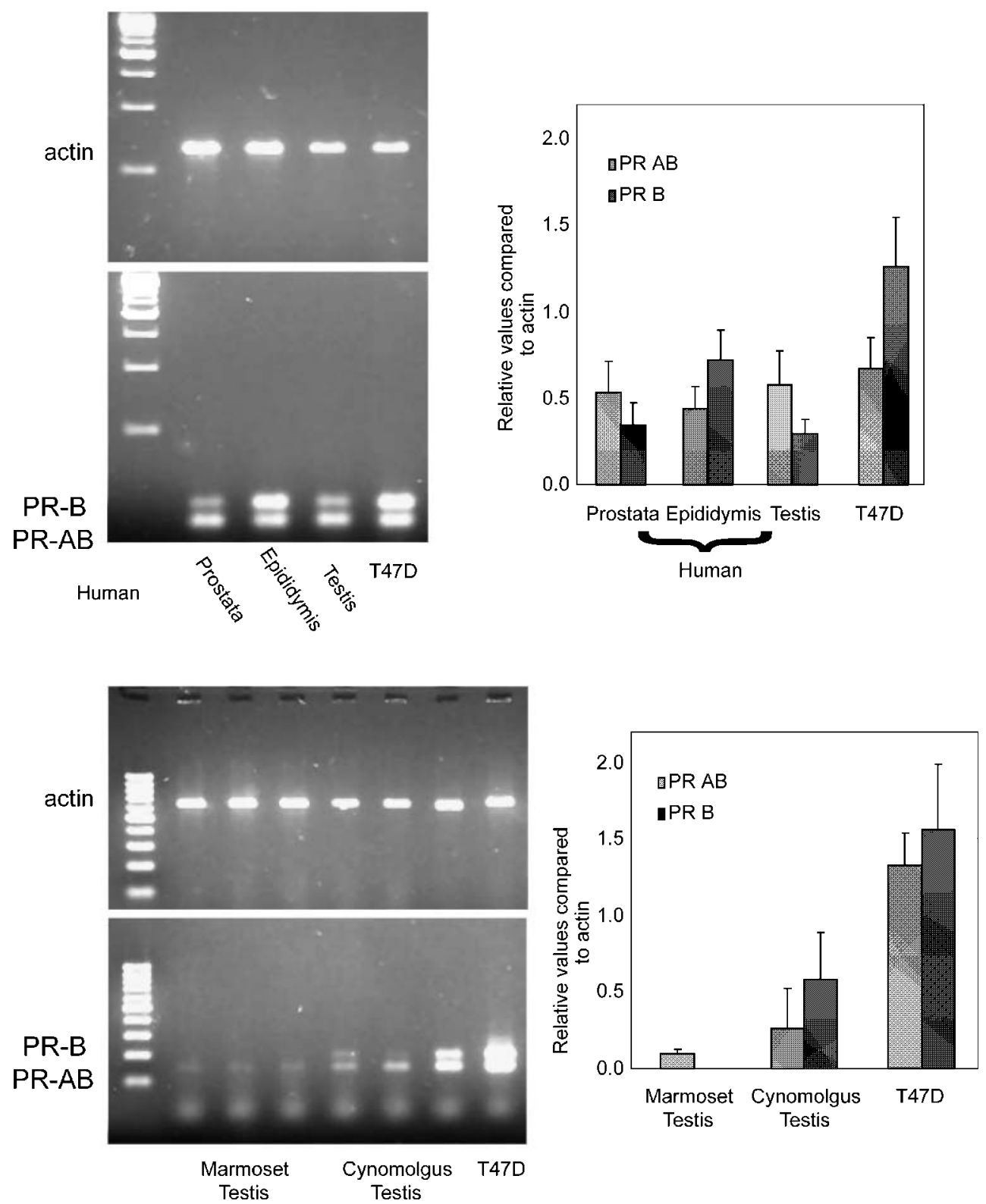

Figure 6 RT-PCR and semi-quantification of the PR isoforms in human, marmoset and cynomolgus monkey tissues. Relative quantification of RT-PCR products was performed by image analysis after normalization against actin. Upper panels: commercially available human mRNA was analyzed along with the positive control T47D. The upper right panel reports relative quantification results of three independent experiments. Lower panels: mRNA was isolated from testes obtained from three different marmoset and cynomolgus monkeys. The PR-A+B transcript was detected in all samples analyzed and was the only transcript in the marmoset testes (left panel). Right panel: relative quantification against actin. Data are given as mean \pm S.D.

$\mathrm{PR}$ involvement in the regulation of the human $\mathrm{GnRH}$ system (An et al. 2004).

In this study we characterized the PR mRNA and protein expression in male reproductive organs such as the testis, the epididymis and the prostate. Our data do not support a major role for progesterone in the regulation of testicular function. Our findings are in agreement with earlier studies in male non-human primates and men (Dube \& Tremblay 1979, Heikinheimo et al. 1995), which were able to locate PR mRNA in the testis and in parts of the epididymis whereby they did not distinguish among the PR isoforms. Our data suggest that both PR-B 
and PR-A are expressed in human and cynomolgus monkey testis. According to our results, confirmed by using different antibodies and equally treated positive controls, some peritubular cells and some interstitial cells are the only source of $\mathrm{PR}$ protein expression, but the low number of positive cells and the absence of $\mathrm{PR}$ protein by Western blotting indicate that primate males have only a very low expression of $\mathrm{PR}$, making a physiological role of progesterone in the testis unlikely.

This result is also consistent with the literature since no other published studies have been able to demonstrate the existence of the PR in the testis, with one exception (Shah et al. 2005). These authors suggested that PR is expressed both in the nuclei and the cytoplasm of male germ cells in a stage-specific manner. However, some methodological aspects should be considered in the interpretation of these results (Shah et al. 2005). First, using tissue collected from cadavers, in situ hybridization revealed mRNA in male germ cell nuclei but not in the cytoplasm, where it would be expected. Secondly, immunohistochemistry data showed possibly unspecific, cytoplasmic staining only on one side of the slides, probably due to fixation or staining artefacts. Thirdly, no positive controls were employed. Using Western blots, bands were seen by loading only $50 \mu \mathrm{g}$ of proteins, while, in the presence of the adequate positive control we could only detect a faint, possibly non-specific band at about $60 \mathrm{kDa}$ by overloading the gels $(800 \mu \mathrm{g})$ in all three primate species tested using four different antibodies. We also trust that our immunohistochemical results are valid because the tissues showed no signs of degeneration due to fixation, embedding or staining. Our histology results (see Figs 3 to 5) are uniform and consistent among three species in which germ cells never showed any staining in the nuclei or the cytoplasm. The possibility that our fixation protocol was too slow, and that the mRNA as well as the protein of the PR was lost due to degeneration, can be excluded because we found the expected PR expression pattern in equally treated tissues of female primates. Therefore, we conclude that the PR is only marginally expressed in peritubular and interstitial cells of human and non-human primate testis.

Tissue culture experiments have demonstrated that smooth muscle cells are a major source of PR mRNA, independent of gender (Hodges et al. 1999). PR expression is stimulated by estrogens. Besides testicular peritubular cells, we found PR expression in smooth muscle cells of the epididymis and prostate. Here the PR could exert a function similar to its role in other smooth muscle tissue cells, i.e. inhibition of calcium-ATPase and regulation of calcium influx, thereby hindering cell contraction and fluid transport (Fomin et al. 1999, Toshima et al. 2000, Saner et al. 2003, Welter et al. 2003). The PR expression found in the fibromuscular cells of the prostate confirms earlier findings in another primate, the rhesus monkey, which was treated with testosterone (West et al. 1988) and in humans with prostate cancer (Wolf et al. 1985).
The peritubular cells of the testis and the epididymal smooth muscle cells are needed to keep a constant flow of tubular and epididymal fluid containing maturing spermatids and sperm. PR might be involved in slowing this movement down. However, in the testis the number of PR-positive cells is very low so that such an effect may be minor. It should be considered that, together with the adrenal gland, the testis is exposed to the highest progesterone concentrations of the body and that the scant PR expression observed could be just a marker of estrogenic activity. As a non-genomic effect, progesterone stimulates sperm hyperactivation and acrosome reaction (Calogero et al. 2000), an effect certainly unwanted in the epididymis. PR expression in the epididymis might alter the flow (Ergün et al. 1997) and could also prevent sperm from premature acrosome reaction. It has been shown that norethisterone enanthate when given with testosterone reduces sperm motility more strongly than testosterone alone (Kamischke et al. 2000a). This is possibly caused by the binding of the epididymal PR to progesterone and decreases its bioavailability for premature sperm activation.

In summary, we have characterized the expression of the genomic PR in a number of male tissues. Our data suggest that genomic actions of progesterone are probably exerted at the hypothalamic-pituitary level, while a direct testicular effect of gestagens is unlikely. Although nongenomic progesterone functions have been found many in vertebrates (Zhu et al. 2003), our recent data showing that norethisterone enanthate has no direct testicular effect in the cynomolgus monkey confirms that gestagens play a very minor role directly in the testis in vivo (Junaidi et al. 2005). In addition, genomic PR is expressed in other organs, where gestagens could affect function when administered for contraceptive purposes.

\section{Acknowledgements}

We thank J Salzig, M Kloth and R Sandhowe for technical assistance, Professor Dr J Gromoll for helping in the gene expression analysis, and S Nieschlag for language editing of the manuscript.

\section{Funding}

The authors declare that there is no conflict of interest that would prejudice the impartiality of this scientific work.

\section{References}

Alexander NJ, Kim HK, Blye RR \& Blackmore PF 1996 Steroid specificity of the human sperm membrane progesterone receptor. Steroids 61 116-125.

An BS, Choi JH, Choi KC \& Leung PC 2004 Differential role of progesterone receptor isoforms in the transcriptional regulation of 
human gonadotropin-releasing hormone (GnRH) I receptor, GnRH I and GnRH II. Journal of Clinical Endocrinology and Metabolism 90 1106-1113.

Baldi E, Krausz C, Luconi M, Bonaccorsi L, Maggi M \& Forti G 1995 Actions of progesterone on human sperm: a model of non-genomic effects of steroids. Journal of Steroid Biochemistry and Molecular Biology 53 199-203.

Brady BM, Anderson RA, Kinniburgh D \& Baird DT 2003 Demonstration of progesterone receptor-mediated gonadotrophin suppression in the human male. Clinical Endocrinology 58 506-512.

Calogero AE, Burrello N, Barone N, Palermo I, Grasso U \& D'Agata R 2000 Effects of progesterone on sperm function: mechanisms of action. Human Reproduction 15 Suppl 1 28-45.

Cheng KW, Cheng CK \& Leung PC 2001 Differential role of PR-A and $-\mathrm{B}$ isoforms in transcription regulation of human $\mathrm{GnRH}$ receptor gene. Molecular Endocrinology 15 2078-2092.

Conneely OM, Mulac-Jericevic B, Lydon JP \& De Mayo FJ 2001 Reproductive functions of the progesterone receptor isoforms: lessons from knock-out mice. Molecular and Cellular Endocrinology 179 97-103.

Dube JY \& Tremblay RR 1979 Search for progesterone receptors in testes from various animal species. Molecular and Cellular Endocrinology 16 39-44.

Ergün S, Ungefroren H, Holstein AF \& Davidoff MS 1997 Estrogen and progesterone receptors and estrogen receptor-related antigen (ER-D5) in human epididymis. Molecular Reproduction and Development 47 448-455.

Fomin VP, Cox BE \& Word RA 1999 Effect of progesterone on intracellular $\mathrm{Ca}^{2+}$ homeostasis in human myometrial smooth muscle cells. American Journal of Physiology 276 C379-385.

Heikinheimo O, Mahony MC, Gordon K, Hsiu JG, Hodgen GD \& Gibbons WE 1995 Estrogen and progesterone receptor mRNA are expressed in distinct pattern in male primate reproductive organs. Journal of Assisted Reproduction and Genetics 12 198-204.

Hodges YK, Richer JK, Horwitz KB \& Horwitz LD 1999 Variant estrogen and progesterone receptor messages in human vascular smooth muscle. Circulation 99 2688-2693.

Junaidi J, Luetjens CM, Wistuba J, Kamischke A, Yeung C-H, Simoni M \& Nieschlag E 2005 Norethisterone enanthate has neither a direct effect on the testis nor on the epididymis: a study in adult male cynomologus monkeys (Macaca fascicularis). European Journal of Endocrinology 152 1-8.

Kamischke A \& Nieschlag E 2004 Progress towards hormonal male contraception. Trends in Pharmacological Sciences 25 49-57.

Kamischke A, Diebacker J \& Nieschlag E 2000a Potential of norethisterone enanthate for male contraception: pharmacokinetics and suppression of pituitary and gonadal function. Clinical Endocrinology 53 351-358.

Kamischke A, Ploger D, Venherm S, von Eckardstein S, von Eckardstein A \& Nieschlag E 2000 b Intramuscular testosterone undecanoate with or without oral levonorgestrel: a randomized placebo-controlled feasibility study for male contraception. Clinical Endocrinology 53 43-52.
Lösel RM, Falkenstein E, Feuring M, Schultz A, Tillmann HC, Rossol-Haseroth K \& Wehling M 2003 Nongenomic steroid action: controversies, questions, and answers. Physiological Reviews 83 965-1016.

Lydon JP, DeMayo FJ, Funk CR, Mani SK, Hughes AR, Montgomery CA Jr, Shyamala G, Conneely OM \& O'Malley BW 1995 Mice lacking progesterone receptor exhibit pleiotropic reproductive abnormalities. Genes and Development 9 2266-2278.

Nieschlag E, Zitzmann M \& Kamischke A 2003 Use of progestins in male contraception. Steroids 68 965-972.

Oettel M \& Mukhopadhyay AK 2004 Progesterone: the forgotten hormone in men? Aging Male 7 236-257.

Saner KJ, Welter BH, Zhang F, Hansen E, Dupont B, Wei Y \& Price TM 2003 Cloning and expression of a novel, truncated, progesterone receptor. Molecular and Cellular Endocrinology $200155-163$.

Schneider J, Sleiter N \& Levine J 1999 Endocrine abnormalities in male mice carrying a null mutation for the progesterone receptor gene. Proceedings of the Endocrine Society 81 2-17.

Shah C, Modi D, Sachdeva G, Gadkar S \& Puri C 2005 Coexistence of intracellular and membrane-bound progesterone receptors in human testis. Journal of Clinical Endocrinology and Metabolism 90 474-483.

Toshima JY, Hirano K, Nishimura J, Nakano H \& Kanaide H 2000 Differential effects of progesterone and 17 beta-estradiol on the $\mathrm{Ca}(2+)$ entry induced by thapsigargin and endothelin-1 in in situ endothelial cells. Biochimica et Biophysica Acta 1499 109-121.

Wei LL \& Miner R 1994 Evidence for the existence of a third progesterone receptor protein in human breast cancer cell line T47D. Cancer Research 54 340-343.

Wei LL, Hawkins P, Baker C, Norris B, Sheridan PL \& Quinn PG 1996 An amino-terminal truncated progesterone receptor isoform, PRc, enhances progestin-induced transcriptional activity. Molecular Endocrinology 10 1379-1387.

Welter BH, Hansen EL, Saner KJ, Wei Y \& Price TM 2003 Membrane-bound progesterone receptor expression in human aortic endothelial cells. Journal of Histochemistry and Cytochemistry 51 1049-1055.

West NB, Roselli CE, Resko JA, Greene GL \& Brenner RM 1988 Estrogen and progestin receptors and aromatase activity in rhesus monkey prostate. Endocrinology 123 2312-2322.

Wolf RM, Schneider SL, Pontes JE, Englander L, Karr JP, Murphy GP \& Sandberg AA 1985 Estrogen and progestin receptors in human prostatic carcinoma. Cancer 55 2477-2481.

Zhu Y, Bond J \& Thomas P 2003 Identification, classification, and partial characterization of genes in humans and other vertebrates homologous to a fish membrane progestin receptor. PNAS $1002237-2242$.

Received in final form 13 March 2006

Accepted 21 March 2006

Made available online as an Accepted Preprint 24 March 2006 